\title{
Earth System Mass Transport Mission (e.motion): A Concept for future Earth Gravity Field Measurements from Space
}

\author{
I. Panet ${ }^{1,2}$, J. Flury ${ }^{3}$, R. Biancale ${ }^{4}$, T. Gruber ${ }^{5}$, J. Johannessen ${ }^{6}$, M. van den \\ Broeke $^{7}$, T. van Dam ${ }^{8}$, P. Gegout ${ }^{4}$, C. W. Hughes ${ }^{9}$, G. Ramillien ${ }^{4}$, I. Sasgen ${ }^{10}$, L. \\ Seoane ${ }^{4}$, M. Thomas ${ }^{10}$ \\ ${ }^{1}$ Institut National de l'Information Géographique et Forestière, Laboratoire LAREG, \\ GRGS, Marne-la-Vallée, France \\ ${ }^{2}$ Institut de Physique du Globe de Paris (IPGP, Sorbonne Paris Cité, UMR 7154 CNRS, \\ Université Paris Diderot), Paris, France \\ ${ }^{3}$ Leibnitz Universität Hannover, Centre for Quantum Engineering and Space-Time \\ Research, Hannover, Germany \\ ${ }^{4}$ CNES, Observatoire Midi-Pyrénées, Groupe de Recherche de Géodésie Spatiale, \\ Toulouse, France \\ ${ }^{5}$ Technische Universität München, Institut für Astronomische und Physikalische \\ Geodäsie, Münich, Germany \\ ${ }^{6}$ Nansen Environmental and Remote Sensing Center, Bergen, Norway \\ ${ }^{7}$ Utrecht University, Institute for Marine and Atmospheric Research, Utrecht, The \\ Netherlands \\ ${ }^{8}$ Université du Luxembourg, Faculté des Sciences, de la Technologie et de la \\ Communication, Luxembourg \\ ${ }^{9}$ National Oceanography Centre, Liverpool, United Kingdom \\ ${ }^{10}$ German Research Centre for Geosciences (GFZ), Potsdam, Germany
}

\section{Corresponding author:}

Isabelle Panet

Institut National de I'Information Géographique et Forestière, Laboratoire LAREG, Université Paris Diderot, Bâtiment Lamarck A, 5 rue Thomas Mann, Case 7011, 75205 Paris Cedex 13, France. Phone: + 331572753 34, fax: + 3315727 XX XX, isabelle.panet@ign.fr 


\begin{abstract}
In the last decade, satellite gravimetry has revealed itself as a pioneering technique for mapping mass redistributions within the Earth system, and has allowed for an improved understanding of the dynamic processes that take place within and between its various constituents. Results from the GRACE (Gravity Recovery and Climate Experiment) mission have revolutionized Earth system research and established the necessity for future satellite gravity missions. In 2010, a comprehensive team of European and Canadian scientists and industrial partners proposed the e.motion (Earth System Mass Transport Mission) concept to the European Space Agency. The proposal is based on two tandem satellites in a pendulum orbit configuration at an altitude of about $370 \mathrm{~km}$, carrying a laser interferometer inter-satellite ranging instrument and improved accelerometers. In this paper, we review and discuss a wide range of mass signals related to the global water cycle and to solid Earth deformations that were outlined in the e.motion proposal. The technological and mission challenges that need to be addressed in order to detect these signals are emphasized within the context of the scientific return. This analysis presents a broad perspective on the value and need for future satellite gravimetry missions.
\end{abstract}

Keywords: Satellite gravity, Earth system, mass transport, global water cycle, Earth deformations

\title{
1. Introduction
}

The large-scale mass distribution in the Earth system is continuously changing. Most of the mass transport is associated with well-monitored atmospheric variability, and with the global water cycle, by which the ocean, atmosphere, land, and cryosphere storages of water interact through temporally and spatially variable water mass exchange (Figure 1). The distribution of water mass in these reservoirs changes at time scales ranging from sub-daily to inter-annual, and decadal, and is strongly related to long term global change, including sea level rise, loss of land ice, and extensive droughts and floods. These mass variations may indicate a change in the forcing or the feedback mechanisms that moderate the climate. Water mass variations may therefore be considered as a proxy for on-going climate change driven by natural and/or anthropogenic causes (e.g. IPCC 4th Assessment Report 2007), which have the potential for very strong societal impacts.

In recent years, for instance, the mass loss of the Greenland ice sheet has been observed to be between 150 gigatons per year $(\mathrm{Gt} / \mathrm{y})$ for years with moderate loss, to up to $280 \mathrm{Gt} / \mathrm{y}$ for years with extensive loss (see e.g., Wouters et al. 2008). This mass loss is attributed to increased glacier discharge and meltwater 
runoff along the margins of the ice sheet, the dynamics of this process and the underlying mechanisms being not fully understood. At contrary, although it undergoes substantial inter-annual variability, the snow accumulation within the ice sheet interior has remained rather stable. Nonetheless, ice mass loss from Greenland contributes to global sea level rise. In addition, the increase of fresh water to the oceans has an impact on the ocean salinity that, in turn, affects the meridional overturning circulation. Of particular concern is that the present observations indicate an acceleration of ice mass loss, not only from Greenland and Antarctica but also from smaller, yet significant, mountain glaciers (Meier et al. 2007; Cazenave and Llovel 2010).

To understand the dynamics and variations of the global water cycle, closing the water mass balance is a fundamental goal. Achieving this goal would allow us to determine how water mass in the Earth's water reservoirs varies in time and space and how much water moves between the various reservoirs (Lettenmaier and Famiglietti 2009). Time-variable ocean mass balance and sea level change is a result of the water balance of all sub-systems. Understanding the global water balance is the key to quantifying the contributions to sea level rise (Cazenave et al. 2009). On regional scales, time-variable water balance reflects changing water availability for drinking water, agriculture and industry. The depletion of freshwater resources is a growing concern for many regions of the world where supplies are under severe threat, and where anthropogenic demands and stresses are expected to further increase in the decades to come (Famiglietti et al. 2011; Rodell et al. 2009).

In addition to the mass changes in the Earth's surface fluid layers, the Earth's crust and interior are also undergoing mass variations that are associated with various kinds of deformations. These include: Glacial Isostatic Adjustment (GIA), visco-elastic response of the solid Earth due to the continental ice mass changes and related sea-level variations associated with the glacial cycles, on time scales of millennia to tens of millennia, elastic surface displacements related to presentday ice mass variations of mountain glaciers and the polar ice sheets, the solidEarth deformation due to earthquakes (i.e. the pre-, co- and post-seismic deformation and the silent earthquakes), and mantle convection and plate tectonics (Vermeersen 2005). These solid Earth mass variations are superimposed on the fluid driven changes. Consequently, the observation and estimation of solid Earth mass variations is necessary not only to study the structure and dynamics of the Earth's interior, but also to derive precise estimates of water mass and sea level change (Tamisiea 2011). In the future, this may include mass change signals due to rising mantle plumes and core motions.

To date, our knowledge of mass transport and mass variations within the Earth system has severe gaps. Many processes related to climate change are poorly understood because direct observations of mass variations and mass transport are often difficult to obtain. For example, no direct observations of 
evapotranspiration (the transport of water from the land surface to the atmosphere) are available. Storage changes in deep soil layers, permafrost and groundwater are also mostly inaccessible to conventional observation (Rodell and Famiglietti 1999; Güntner 2008). The same holds true for the deep ocean circulation, which is an essential part of the climate system, playing an important role in heat transport and carbon dioxide sequestration. In addition, the scarcity and often poor accuracy of high-latitude data, the lack of precise measurements of freshwater run-off and the limitation of conventional observation techniques along coasts and ice sheet margins (Dexter and Summerhayes 2010, Rignot and Thomas 2002), results in incomplete and biased results with regard to closing of the water balance.

Satellite gravimetry, i.e. measuring spatial and temporal change in the gravity field caused by mass variations, provides a unique technique to advance studies and improve our understanding of the Earth system. From the GRACE mission (Tapley et al. 2004), new fundamental insights into changing mass distribution have been achieved in the last decade (For a recent review the reader is referred to Cazenave and Chen (2010), which provides an extensive review of results concerning mass distribution that has been compiled from a large number of research papers. Recent results are also presented in Kusche et al. 2012). The GRACE mission has been extremely valuable in providing insight into continental hydrology (see the recent reviews by Güntner 2008; Ramillien et al. 2008; Schmidt et al. 2008), with a main focus on large-scale seasonal signals, and the effects of hydro-meteorological extremes such as droughts and floods. The decade of GRACE data have demonstrated beyond a doubt that glaciers in Alaska and Patagonia as well as the great ice sheets of Greenland and Antarctica are losing mass (Tamisiea et al., 2005; Chen et al., 2007; van den Broeke et al. 2009; Velicogna 2009). This finding has ended the debate as to whether the ice sheets and glaciers are contributing to ongoing sea level rise. The GRACE measurements have been essential to closing the sea level budget at the global scale (Milne et al. 2009; Cazenave and Llovel 2010). Gravity field variations related to the GIA have supported the hypothesis that the Pleistocene ice sheets over Canada consisted of two major domes (Tamisiea et al. 2007), even though part of the interpreted GIA pattern may have been hydrological mass variations (van der Wal et al. 2008; Sasgen et al. 2012). In addition to GRACE, the GOCE satellite provides unprecedented maps of the static geoid and gravity field (Rummel 2011; Pail et al. 2011) since 2009. GOCE is providing synergetic information on the ocean circulation and other Earth system processes as well as on lithospheric structure.

Mass variations within the Earth system occur over a wide range of spatial scales as illustrated in Figure 2. For instance, GRACE in combination with other satellite data can now resolve changes on the order of a few millimeters equivalent water height $(\mathrm{EWH})$ and long-term trends exceeding $0.5 \mathrm{~mm} /$ year at scales of $1000 \mathrm{~km}$. At a spatial resolution of approximately $400 \mathrm{~km}$, on the other hand, detection is 
limited to only mass changes with an amplitude of $10 \mathrm{~cm} \mathrm{EWH} \mathrm{-} \mathrm{or} \mathrm{trends}$ exceeding $1 \mathrm{~cm} / \mathrm{yr}$. While this is an enormous improvement on the situation before the launch of GRACE, many mass signals from very different processes that are relevant to Earth system research remain beyond the current limit of resolution. This includes continental hydrology and ice mass change at smaller scales, many small amplitude signals in the ocean, and all but the very largest signals from solid Earth mass variations. To access the band beyond the current limit of resolution and to address many remaining open questions, higher spatial resolution, higher accuracy and extended data records are essential. This can be achieved by improved measurement precision and by an optimized orbit configuration enhancing the satellites sensitivity to the Earth's gravity field. Apart from some supporting instruments, measurement precision, in particular, can be increased by replacing the conventional microwave inter-satellite ranging system with a laser interferometer, while sensitivity can be increased by lowering the orbit as compared to the current GRACE mission. The next dedicated gravity field mission will be the US-German GRACE Follow-On mission, planned for launch in the $2016 / 2017$ timeframe. This mission is planned to carry an experimental laserinterferometric inter-satellite ranging instrument in addition to the microwave ranging system. The Earth System Mass Transport Mission, called "e.motion" that was proposed to ESA by a comprehensive team of European and Canadian scientists, engineers and industrial partners builds on this innovation and associated studies. Although e.motion was not selected by ESA, the interest of such mission concept was underlined.

In this paper the science justification and requirements of the e.motion mission concept is presented and discussed. The concept builds on previous studies, in particular from Beutler et al. (2003), Flury and Rummel (2005), Koop and Rummel (2008), and from the Graz workshop "Towards a roadmap for future satellite gravity missions" (2009). As such it represents a broader perspective on satellite gravimetry. Section 2 addresses the Earth system gravity signals of mass changes at the finer spatial scales not resolved by GRACE specifically targeting: (1) recovery of temporal gravity and mass variations in the Earth system with a spatial resolution of $200 \mathrm{~km}$ or better, with global coverage; (2) recovery of small amplitude mass variations with 10 times increased sensitivity compared to current capabilities; (3) resolution of mass variations at seasonal to decadal time scales, by extending the existing record of satellite data by 7 years or more with enhanced quality and with a temporal resolution of 1 month or better. Section 3 reviews the corresponding challenges regarding technology and mission system requirements. The conclusion then follows in Section 4.

\section{Earth's system signals beyond the current limits of GRACE}

\section{1 - Estimating continental water storage and freshwater fluxes}


Continental water storage is a key component of the global water cycle, and plays a major role in the Earth's climate system. Through the processes of precipitation, evaporation, run-off at the surface and at depth, it governs the exchanges of water between continents, oceans, atmosphere and ice caps, controlling energy and biogeochemical fluxes. It comes in many forms, such as snow, ice, surface water, soil moisture and groundwater. Knowledge of its spatial and temporal variations is required to infer changes in the processes affecting the water cycle. By closing the water balance equation, components such as groundwater can be estimated. However, this is made possible only by the availability of integrated mass change derived from gravity observations (Schmidt et al. 2006; Ramillien et al. 2008). Separating the contributions of water mass sub-reservoirs (i.e., surface waters, soil moisture, ground water) is thus a challenge for the next GRACE-type mission, especially to estimate deep water changes that globally remain unknown.

In many regions however, zones of different hydrological behaviour are spatially too close to each other to be separable by GRACE. This refers to different climate zones or important water storage reservoirs such as aquifers, glaciers, or flood plains, which all have strong impacts on the local environment and climate such as ecosystems, agriculture, and the supply of freshwater. Capturing their different temporal dynamics is essential to understanding the impact of environmental variability and change on the continental water cycle and future water availability.

Furthermore, improving the spatial resolution to $200 \mathrm{~km}$ or better would provide hydrological data at scales that are the most relevant for operational applications in water resources management. With a $400 \mathrm{~km}$ resolution, water storage changes can be resolved for $18 \%$ of the 182 major drainage basins of the world only. With $150-200 \mathrm{~km}$ resolution achievable by laser inter-satellite ranging, basins of $40000-22000 \mathrm{~km}^{2}$ will be resolved, representing about $75 \%$ of the major basins (Oki and Sud 1998), as shown on Figures 3 and 4.

When lateral transports are sufficiently well observed in individual basins by complementary measurements from e.g., river gauges or groundwater wells, water storage variations can be related to changes in atmospheric freshwater fluxes by evaluating the water budget equation. While precipitation is remotely observed by combining satellite scatterometer measurements with infrared radiances and ground precipitation radars, evapotranspiration is particularly difficult to measure even from in-situ observations due to its high spatial variability. Satellite gravity data at higher spatial resolution than GRACE would thus allow derivation of regional estimates of these fluxes, which might be assimilated in order to improve the large-scale freshwater balance of numerical weather prediction models.

Observations of water storage changes via satellite gravimetry indeed give access to one of the very few large-scale observation data sets that are available 
to evaluate and constrain hydrological models or land surface schemes in climate models and weather forecast models. They allow to develop and constrain global and regional hydrological models and improve their prognostic capabilities. Moreover, water storage time series at the same spatial scale as river discharge measurements, i.e. sub-basins, allow for a consistent improvement of hydrological models. Indeed, both variables provide an integrated measure of the river basin response and can thus be used simultaneously as model constraints.

Finally, long-term satellite gravity measurements are needed for adjusting model equations and parameters that are relevant for long-term hydrological processes. Even if a model reasonably represents the seasonal hydrological cycle, this does not guarantee a realistic model performance for inter-annual variations. The availability of long time series will also allow addressing another challenge, which is to separate the natural variability in continental water storage from human-induced changes, such as by the exploitation of water resources, land use change or climate change, that produce gradual changes in the water cycle.

\section{$\underline{2.2 \text { - Understanding ice sheets mass balance }}$}

Ice sheets, smaller ice caps and valley glaciers, store most of the Earth's freshwater. Ice mass is accumulated by precipitation, and ablated by glacier discharge to the ocean, by melt, sublimation, and evaporation. The net balance between the inflow and outflow components of ice mass reacts sensitively to climate change. At present, ice mass loss prevails, contributing more than one half to the on-going global sea level rise in recent years (Cazenave and Llovel 2010).

Many fundamental research questions remain unresolved in this field. We do not know in detail the physical processes that are most relevant for glacier acceleration in Greenland and West Antarctica (Rignot and Thomas 2002, Zwally et al 2002; IPCC 2007; Pritchard et al 2012). Due to the complexity of the ice dynamic behaviour, it is highly uncertain how the mass loss will evolve in the future, and whether the West Antarctic ice sheet may disintegrate at some point (Hughes 1973; Thomas et al 1979). At present, we cannot separate mass movement caused by GIA with sufficient accuracy from contemporary ice sheet mass changes (Barletta et al. 2008). We do not know whether the current trends reflect a long-term behaviour of the ice sheets, or whether they are part of the decadal variability of the ice sheet climate system. Smaller glaciated regions (Svalbard, Arctic Canada, Alaska, Patagonia, ...) are important contributors to present-day sea-level change (Meier et al. 2007), yet currently poorly resolved.

These processes involve significant variability at scales beyond the limits of resolution of GRACE. To answer the open questions, it will be necessary to resolve ice mass change at the glacier basin scale. Increasing the spatial 
resolution from $400 \mathrm{~km}$ to $200 \mathrm{~km}$ or better, which can be achieved by a mission in an e.motion configuration, will be a major step forward for the recovery of ice mass variations. The number of resolvable glacier basins within ice sheets (Rignot and Kanagaratnam 2006; Rignot et al. 2008) will be more than doubled, e.g., for Greenland it would increase from 16 basins presently resolved to 43 basins of size of $40,000 \mathrm{~km}^{2}$ (Figure 5 ). In addition, the higher resolution will increase the comparability with satellite laser and radar altimetry data, and the possibility of the combination of different observational types.

The increased resolution will strongly enhance the value of observed mass variations for data assimilation into regional climate and ice-dynamic models, as the net mass balance and its components of accumulation, melting and glacier discharge are regionally highly heterogeneous. It will strengthen the role of satellite gravimetry as a unique constraint on ice sheet mass variations, in combination with the mass budget method, satellite altimetry and in-situ measurements. This will shed light onto the processes driving ice dynamics at high resolution, and support the development of ice dynamical models. The dynamics in the ablation zone around the Greenland ice sheet will be captured, including inter-annual mass variations that may have varying characteristics in the different regions of the margins of Greenland (Wouters et al. 2008; Van den Broeke et al. 2009). By synthesizing the high-resolution observations with models, it will be possible to quantify whether individual glacier systems lose mass by glacier acceleration or by surface melt. For the Antarctic Peninsula, it will be possible to determine how glacier discharge rates are affected by the ice shelf disintegration. It will be possible to follow the behavior of the glacier systems in the Amundsen Sea Embayment, which is considered to be a key region of the West Antarctic ice sheet due to its extreme ice-flow velocities and ongoing glacier thinning and retreat, and to monitor variations along the margins of East Antarctica that appear to be losing mass according to recent gravity data (Chen et al., 2009). Finally, continuous time series of measurements with improved accuracy will help to quantify the teleconnections (e.g. ENSO, SAM, NAO) between the ice sheets in the global climate system (Sasgen et al. 2010). This will contribute to deciphering the long-term trends in the interannual variations of polar ice sheetsmass balance associated with changes in the climate system.

\section{$\underline{2.3 \text { - Understanding changes in sea level and monitoring the large scale }}$ ocean circulation}

The oceans are an essential component of the climate system. They play a major role in storing, transporting and redistributing heat within the Earth system, because of their immense heat capacity. Moreover, precise quantitative and multidisciplinary understanding of the processes that influence sea level change is one of the major concerns of our time. Continued satellite gravity time series with enhanced accuracy will provide clearer insight into the time scales of 
variation of the mass components of the sea level budget, and will allow a better separation between density and mass contributions to sea level change. This will be necessary in making projections of future sea level rise.

An important regulator of climate is the deep ocean circulation. At depths greater than $2000 \mathrm{~m}$, the limit of most Argo floats, there are very few ocean monitoringsystems. Yet flow at these depths, plays an important role in global heat transport and the meridional overturning circulation. Via ocean bottom pressure sensing, satellite gravimetry measures the integrated mass change from the near-surface waters down to the bottom boundary layer. This partly overcomes the limited availability of direct observations at depths below $2000 \mathrm{~m}$. It is advantageous that, whereas sea level is dominated by mesoscale (about 10-300 km) variability, bottom pressure tends to vary on much larger length scales and hence filters out much of the mesoscale variability (Bingham and Hughes 2008a). This, coupled with the strong dynamical constraints on bottom pressure variability (Hughes and de Cuevas 2001), makes bottom pressure a particularly suitable quantity for monitoring large-scale changes in the deep ocean circulation (Bingham and Hughes 2008b). Spatial gradients of ocean mass anomalies allow for the derivation of barotropic ocean currents and, hence, transports (Zlotnicki et al. 2007). However, bottom pressure is a challenge to measure, as the signals are small, and averaging over large areas is required to obtain reasonable estimates. A typical amplitude for bottom pressure variability is 3-5 times smaller than for sea level, and this signal is dominated by high-frequency depth-independent changes that are also visible in sea level, and of little relevance to heat transport; the signal of climatic importance is smaller again (Bingham and Hughes 2008a).

Probably the most valuable measurement related to bottom pressure is that of the Atlantic meridional overturning circulation, responsible for a large fraction of the total ocean heat transport. This is associated with a highly distinctive pattern of bottom pressure variability concentrated on the continental slope of the American continent. With typical spatial scales of approximately $70 \mathrm{~km}$ across the slope, and thousands of kilometres along the slope (Roussenov et al. 2008; Bingham and Hughes 2009), and associated signal amplitudes of a few centimetres EWH, this signal is far too small for detection by GRACE. However, with dedicated processing that is focused on the distinctive pattern of the signal, a higher-accuracy mission such as that outlined in the e.motion proposal may make it possible to detect this mode of variability. The poor observational constraints on deep ocean dynamics mean that measurements such as this will be highly valuable both for validation and initialization of the ocean component of numerical Earth system models.

Regarding sea level, GRACE results have demonstrated both the value and the major sources of uncertainty in estimating changes in global ocean mass from satellite gravimetry. There remain three particular sources of error, each of which may be reduced if higher spatial resolution is attained. 1) The gravitational effect 
of GIA, which produces a signal of about $1 \mathrm{~mm} / \mathrm{yr} \mathrm{EWH}$ when integrated over the ocean, and presently has uncertainties of about half that size (Tamisiea 2011); this error source will be reduced by improved GIA models which would result from satellite gravity data with higher accuracy and resolution. 2) Low spatial resolution results in a blurring of the ocean-land boundary that introduces uncertainty in the associated estimates of ocean mass changes, producing potential errors of more than $30 \%$ in the contributions from Greenland and glacier melt (Chambers et al. 2007), and variations of up to $0.4 \mathrm{~mm} / \mathrm{yr}$ in corresponding GIA corrections (Tamisiea 2011); higher resolution would clearly reduce this error source. 3) Lack of information about geocenter motion in the gravity field data leads to a further reduction in estimated Greenland and glacier contributions, increasing the error to more than $60 \%$ unless correctly accounted for (Chambers et al. 2007); finer spatial resolution would make no direct improvement in this error, but would enable better combination with the local, Earth-based measurements, which must be combined with satellite gravimetry to provide an estimate of the geocenter motion.

Increased spatial resolution and accuracy of gravity data will also be highly beneficial for regional oceanographic applications such as assessing sea level change for shelf areas along densely populated coasts. Having access to mass changes at a spatial resolution of about $200 \mathrm{~km}$ would also, in combination with GOCE, potentially allow for improved knowledge of the static geoid. Hence, the mean dynamic topography could be provided with a possible accuracy of $1-3 \mathrm{~cm}$ from about $100 \mathrm{~km}$ to $70 \mathrm{~km}$. In turn, the mean surface geostrophic currents along intense current regimes would expectedly benefit from the present strength achieved with GOCE.

\section{4 - Measuring and modelling the Glacial Isostatic Adjustment, large earthquakes and slow tectonic motions}

Accurate modelling of the deformation of the solid Earth, e.g. due to earthquakes and slow deformations such as GIA, requires a good knowledge of the Earth's internal structure. When it comes to understanding the density distribution inside our planet, significant advances are expected from the GOCE static gravity field observations. Another important, yet poorly known property of the Earth's interior is the mantle viscosity. It controls the pattern of convective flow, the viscous deformations of the Earth in response to various internal and external forces, and the stress distribution in subduction zones, which are affected by the largest and most violent earthquakes. Laboratory experiments are insufficient for inferring the Earth's viscosity, as realistic mantle temperatures and pressures are difficult to simulate in a laboratory. These limitations make geophysical observations of geoid changes, GIA, and observations of post-seismic deformation extremely important (Hager 1991; Wu and Peltier 1983; Mitrovica and Forte 1997; Pollitz et al. 2001). 
GIA alters the Earth's gravity field as a consequence of mass redistribution within the Earth's mantle, as well as by deforming the Earth's surface. Despite observations such as indicators of paleo sea-level change, GPS and tide-gauge measurements, determinations of GIA and inferences about the mantle viscosity remain ambiguous. Moreover, measuring GIA is difficult because many regions where we would expect to observe the visco-elastic response to the melting of the Pleistocene glaciers, i.e. the edges of large ice sheets, are also affected by elastic surface displacements due to present day changes in ice mass e.g. in Alaska, Greenland and Patagonia (Barletta et al. 2008). For Antarctica, limited accessibility and sparse paleo constraints on GIA have led to a particularly large uncertainty of GIA predictions, which are, however, crucial for determining accurate ice-mass balance estimates from satellite gravimetry. Currently, uncertainties in the GIA corrections thus overprint ice mass variations in Antarctica. Here, a new gravity mission will contribute to the regional separation of present-day ice-mass changes from GIA, and provide valuable data to be included in visco-elastic modelling. This will also better resolve the GIA contribution to estimates of sea level change (see the section above on sea level change).

Due to its spatial coverage, satellite gravimetry is a unique new constraint on the spatial pattern of GIA and, subsequently, on the mantle viscosity and lithospheric thickness (Paulson et al. 2007), and on the ancient ice geometry (Tamisiea et al. 2007). To better distinguish between plausible Earth viscosity profiles, GIA signals must be recovered with a considerably higher accuracy than provided by GRACE (Wahr and Davis 2002). Analysis of longer time spans of satellite gravity data should also allow us to separate more clearly inter-annual hydrological and cryospheric mass variations from the GIA signal. . Improving numerical models with the recent climate change records will further enhance capabilities to simulate long-term cryospheric mass fluxes and separate them from changes induced by GIA. Finally, combining the estimated GIA trends with the static freeair gravity data from the region, which will be considerably improved thanks to GOCE, makes it possible to derive important boundary conditions on the buoyancy of the continental tectosphere (Tamisiea et al. 2007).

At smaller spatial and temporal scales, the study of solid Earth deformations associated with earthquakes would greatly benefit from high-resolution satellite gravity data. The most devastating earthquakes of the modern epoch have all occurred at subduction zones, causing huge damage in densely populated areas. In these highly seismically active regions, satellite gravity data are extremely valuable for constraining the rupture mechanism and quantifying post-seismic deformation, because they cover undersea epicentral areas that can hardly be surveyed by ground geodetic and geophysical techniques (Mikhailov et al. 2004; Han et al. 2006). By monitoring the seismic cycle and slow aseismic motions, satellite gravity can contribute to a better understanding of the mechanisms of stress accumulation and stress release. Observations of post-seismic response 
can be used to determine the relative importance of afterslip and visco-elastic relaxation and constrain the shallow rheology and viscosity of the Earth (Panet et al. 2010). This information can then be extrapolated to other earthquake-prone regions. A higher spatial resolution and accuracy is however needed in order to detect the gravitational changes associated with earthquakes of Mw 7 to 8 (de Viron et al. 2008).

\section{5 - Providing the gravity reference in the Global Geodetic Observing System}

Better knowledge of time variable gravity and mass distribution will also - directly or indirectly - improve the accuracy of of Earth observation systems and techniques. Mass changes, such as changing water loads, deform geodetic networks such as Global Navigation Satellite Systems (GNSS) ground station networks. Changing mass distribution also has an influence on orbits and orbit determination for low Earth observation satellites, and manifests itself with complex signatures in Earth rotation and observed Earth orientation parameters. More accurate Earth gravity field models will help to improve the accuracy of orbit modeling and reduce the effect of orbit errors on satellite observations. Consistent combination of more accurate satellite gravity data with geometric techniques such as GNSS, VLBI, and Satellite Laser Ranging, will further improve knowledge on mass change, and it will help to resolve techniqueinherent error sources. This will also improve the International Terrestrial Reference Frame underlying the observation techniques. Mission concepts such as e.motion are needed to advance the implementation of the Global Geodetic Observing System (Plag and Pearlman 2009).

An accurate geoid is needed as a reference for precise height determination. At this time, the GOCE satellite mission is carrying out observations to determine an excellent, high-resolution quasi-static geoid. In many regions, however, heights are affected by significant temporal geoid changes, e.g., due to GIA. Temporal geoid changes observed by future satellite gravimetry, combined with the GOCE quasi-static geoid, will reduce inconsistencies between national height systems, and advance the establishment of a World Height System for science, engineering, mapping, and Geographical Information Systems (GIS).

\section{$\underline{2.6-\text { Summary of e.motion science requirements }}$}

Mass variations associated with the above-described processes occur on a wide range of spatial and temporal scales, as illustrated in Figure 2. More specific information on their time scales and amplitudes, and on the required precision and resolution to recover these signals from a gravity mission, is given in Table 1. The precision is estimated at $10 \%$ of the signal amplitude. For most research 
objectives, specifications are given in terms of $\mathrm{EWH}$, but they are provided in terms of geoid or gravity variations where appropriate. The conversion between equivalent water height and geoid variations depends on the spatial scale and it is described in Appendix 1. Previous comparable Tables were given by Sneeuw et al. (2005) and Rummel (2005).

In the following, we give some examples on how to read Table 1. For instance, seasonal variations of hundreds of $\mathrm{mm}$ of equivalent-water height have been detected by GRACE in large tropical basins (around +/-500 mm in the Amazon basin, Ramillien et al. 2008). Measuring water height variations with a $10 \mathrm{~cm}$ precision at $150-200 \mathrm{~km}$ resolution would allow us, for instance, to recover mass variations in basins such as the Rhine and Danube catchments, which cannot be studied with available data. At scales shorter than $200 \mathrm{~km}$, the capabilities of a satellite gravity mission based on the e.motion concept to resolve mass variations would be reduced. However, large mass variations such as those associated with heavy snow accumulation and floods could be recovered and quantified at scales of around $100 \mathrm{~km}$. This length scale also corresponds to the typical size of glaciers terminating in the coastal areas of the polar ice caps, areas of crucial interest since they contribute a large part of ice mass loss and are not fully covered by altimetry.

Concerning sea-level, the current rate of global sea level rise is $3.3 \pm 0.4 \mathrm{~mm} / \mathrm{yr}$ (Cazenave and Llovel 2010). An acceleration of $1 \mathrm{~mm} / \mathrm{yr}$ over a decade would be a large signal, so the accuracy in the monitoring of the mass component of the sea level signal should be sufficient to detect an acceleration of $0.1 \mathrm{~mm} / \mathrm{yr}$ over a decade, requiring an accuracy of 0.5 to $1 \mathrm{~mm}$ of EWH. For regional ocean dynamics, a typical requirement for sea level from altimetry is $1 \mathrm{~cm}$ accuracy but bottom pressure signals are weaker by typically a factor of 3 to 10 , leading to a requirement of a few $\mathrm{mm}$ of water accuracy at regional scales.

Concerning solid Earth signals, a study of geoid variations at GRACE resolution associated with earthquakes of varying magnitude can be found in de Viron et al. (2008), while Mikhailov et al. (2004) showed that a mission 10 times more precise than GRACE would allow for the detection of the accumulation of mass along active tectonic zones, discrimination of fault plane models, and the monitoring of asperities on locked seismic zones. Finally, the amplitude of the GIA signal over the Hudson Bay is of magnitude 1-2 mm/yr on the geoid (Barletta and Bordoni 2009), however, distinguishing GIA signals associated with different viscosity profiles within the Earth require a significantly higher accuracy (Wahr and Davis 2002; Vermeersen, 2005).

\section{Technological and mission configuration challenges}

To observe the mass variation signals discussed in the previous section, an enhanced precision of the inter-satellite ranging measurement system is needed, 
as well as global coverage with sub-monthly temporal sampling. In this section, these requirements are discussed in the context of the corresponding satellite system challenges.

\subsection{Technological challenges}

In order to reach the scientific mission goals as described in the previous section, the measurement precision as compared to what is achievable with the GRACE mission needs to be enhanced significantly. As the primary instrument the microwave ranging system as implemented on GRACE needs to be replaced by a laser interferometric ranging system offering a significantly higher precision of the inter-satellite range measurements. The sensor configuration design for such a system has been recently studied by Sheard et al. (2012). The laser interferometer system is based on the transponder principle: laser beams (1064 $\mathrm{nm}$ wavelength) are transmitted from each satellite towards the twin satellite. Laser frequencies are locked onboard one satellite. On the other satellite, interferometric phase readout is carried out, and the phase variations are converted to equivalent changes in the inter-satellite distance, with a noise level of $50 \mathrm{~nm} / \mathrm{sqrt}(\mathrm{Hz})$ or better. This represents a sensitivity gain of a factor of 50 as compared to GRACE, although this term remains far from the technological limit of laser interferometric ranging.

Accelerations originating from non-gravitational forces have to be observed within a dedicated measurement range with a high-sensitive 3D accelerometer. For the e.motion mission design, one needs an accelerometer with a noise level of $10^{-11}$ to $10^{-12} \mathrm{~m} / \mathrm{s}^{2} / \mathrm{sqrt}(\mathrm{Hz})$, which corresponds to a factor of 10 to 100 improvement in performance as compared to the GRACE accelerometer. Six of such accelerometers forming a gravity gradiometer are presently operating in the GOCE mission. From the results obtained with GOCE, it can be shown that this accuracy level is achievable when a partial or full drag compensation is implemented (specifically having in mind the lower altitude of $370 \mathrm{~km}$ considered for e.motion). Drag compensation is needed in order to improve the resolution of the accelerometers by reducing their measurement range. As it is planned to fly the mission in a so-called pendulum configuration (see below) the flight direction usually is not in-line with the line of sight between both satellites. For this reason an accelerometer with three high sensitive axes is needed in order to map the non gravitational accelerations observed by the three axes to the flight direction, where the main disturbing accelerations happen. This is a major difference to the GRACE configuration, where line of sight and flight direction mostly are in line or deviate only by very small angles.

Finally, as a result of the pendulum orbit configuration (see Figure 6) together with the pointing requirements for the laser interferometer, which are much higher as compared to the GRACE microwave system, an innovative attitude 
determination and control system needs to be implemented. This includes a new class of thrusters, which are capable of orienting both satellites permanently with respect to each other with high precision. For this purpose electric propulsion systems have been identified in the e.motion proposal as the primary choice, despite the fact that their technological readiness has not yet been established.

The position of the satellites has to be observed by GNSS space receivers capable to observe signals from any available global navigation system (for e.motion specifically a GPS and Galileo receiver is foreseen). Having available signals from more navigation satellites would further improve the determination of highly accurate orbits, which are the starting point for gravity field analysis.

\subsection{Orbit configuration}

The orbit configuration has to ensure that global measurements, including the poles, are feasible, and that the satellites revisit every location with a repeat cycle shorter than one month. The latter is needed in order to make sure that time variable mass signals can be observed at a constant rate with comparable spatial resolution. This leads to the choice of a near "true" polar orbit with an inclination close to 90 degrees. The altitude should provide both excellent sensitivity to the gravity field and offer a sufficiently quiet environment. In the e.motion configuration, satellites are maintained at approximately $370 \mathrm{~km}$ altitude. At this orbit height, a repeat period of 28.92 days with an equatorial inter-track distance of about $44 \mathrm{~km}$ can be reached. The inter-satellite distance should be commensurate with the target gravity field resolution, about $200 \mathrm{~km}$. To achieve homogeneous quality for mass variation results and to overcome limitations of uni-directional ranging observations, we chose a pendulum orbit configuration. By rotating the orbital planes relatively to each other (by change of the right ascension of the ascending node), observations are obtained not only in the North-South direction, but also in other directions, with a maximum tilt of $15^{\circ}$ at the equator (see Figure 6). As simulations have shown, this strategy would improve the isotropy of the estimated gravity field signals significantly implying that the well known North-South stripes seen in the GRACE monthly fields can be strongly reduced. With such a configuration it is no longer expected that there will be a need for dedicated post processing filters, which to some extent also reduce the signal. With a minimum mission duration of 7 years in such an orbit configuration, we expect that long-term mass variation signals can be determined with the required accuracy and spatial resolution.

\subsection{Quality of gravity field retrieval}

To assess the quality of gravity and mass variation retrievals in the e.motion configuration, many simulations have been carried out (Johannessen et al. 2010). Compare also Visser et al. (2010), Loomis et al. (2011) and Wiese et al. (2012). 
Figure 7 shows two resulting error spectra in terms of spherical harmonic degree, in units of equivalent water height per degree (standard deviation), for a timespan of one month of data. Simulations include interferometer errors and accelerometers errors. In addition, model noise arising from so-called geophysical background models for mass variations has also been introduced. These background models for tides, non-tidal oceanic and atmospheric mass variations are needed to mitigate the effect of aliasing caused by the rapid mass variations that are undersampled by the satellite pair - note that the 10 days repeat sub-cycle of the e.motion orbit allows a direct observation of part of these submonthly variations. Here, model noise has been estimated by computing and scaling differences between several background models. To make the simulation results comparable with the signal scales and amplitudes outlined in Figure 2 and Table 1, the spherical harmonic coefficient standard deviations have been converted to regional error estimates according to Appendix 2. These errors are represented by the two yellow curves depicted in Figure 2. Note that these should be considered as rough error estimates, in particular due to the uncertainty of the model noise estimates.

\section{Conclusion}

By monitoring large-scale water fluxes and solid Earth deformation, GRACE has proved to be a pioneering technique for assessing Earth system mass changes and has revolutionized research in many fields of application. The outstanding results obtained, together with the need to understand long-term variations driven by climate change, provide a strong motivation for ensuring continuity of future time-varying satellite gravity missions.

By reviewing Earth system mass signals, we clearly find that beyond the current limitations of satellite gravimetry, there remains a large ensemble of important processes, which may be accessible with upcoming technological improvements. This implies advances in terms of spatial resolution, retrieval accuracy and length of records, confirming results of earlier assessments in this field. We underline the associated challenges, both in terms of the measurement system and the configuration of a laser interferometric ranging mission. With the e.motion configuration, the mass signals discussed here can be retrieved meeting the requirements given in Table 1.

As gravity measurements provide an integrated view of the mass variations, their interpretation in terms of mass transport is inherently multi-disciplinary. Satellite gravimetry is thus a vital component of a multi-sensor Earth observing system, which complements and relates observations of different Earth system constituents in a common and consistent global framework. 
The mapping of mass variations and fluxes at the spatial resolution of most basin systems, jointly analyzed with the complementary datasets and models for the different system compartments, will become a central element in the derivation of a more accurate global view of the ongoing interacting processes and the impact of climate variations on the Earth's equilibrium. Being closely related to changes in sea level, glaciers and ice caps, groundwater, river discharge, snow cover and other variables in the set of Essential Climate Variables (ECVs) established by the Global Climate Observing System (GCOS) initiative (GCOS 2003, 2006), mass change observations by means of satellites has the potential to significantly improve knowledge for these ECVs, and might even be considered an ECV on its own if satellite gravity missions are continued in the future.

\section{Acknowledgements}

This paper is based on the comprehensive work and analysis realized to prepare the e.motion proposal, in response to the European Space Agency Call for proposals Earth Explorer Opportunity Mission EE-8. As such, the results

presented here greatly benefited from numerous inputs and discussions with the members of the e.motion science team, listed in Appendix 3. We gratefully thank them for their contributions. Industrial support was provided from SpaceTech $\mathrm{GmbH}$ Immenstaad and from the Office National d'Études et de Recherches Aérospatiales. We thank Michel Diament for helping us to improve this manuscript. We are grateful to the Editor, Anny Cazenave, and two anonymous reviewers, for their suggestions that contributed to improve this manuscript. Work by Isabelle Panet, Richard Biancale, Pascal Gegout and Guillaume Ramillien was supported by CNES (Centre National d'Etudes Spatiales) through the TOSCA committee. This is IPGP contribution number XXX. 


\section{Appendix}

\section{A.1 - Amplitude of geoid variations associated with local water loads}

The amplitude of geoid variations associated with a water mass load depends on the spatial scale of this load, as shown in Wahr et al. (1998). Here, we computed the geoid effect of a water load spatially distributed as a Gaussian bell, with an amplitude of $1 \mathrm{~cm}$ of equivalent water thickness at the center of the Gaussian. We considered the direct Newtonian attraction of the load, and the Earth's elastic deformation as given by the Love numbers. Results are provided in Table 2 for a Gaussian bell of varying radii $r$. The radius corresponds to the distance to the center for which the water thickness has decreased by a factor of two. These

results allow for easier conversions between equivalent water height $(E W H)$ signals and geoid variations. 


\section{A.2 Local error estimates}

Earth system mass signals associated with various physical processes are most often local. This means that the estimates of the precision required to recover those signals should be local. Here we recall, following Dickey et al. (1997) and Wahr et al. (1998), how they are related to global spherical harmonics error spectra.

Let $h(\theta, \varphi)$ denote the water height at the point of co-latitude $\theta$ and longitude $\varphi$, and the average error over an area of interest. A localizing filter $W(\theta, \varphi)$ is associated with this area, describing its shape. However, because of the limited resolution of satellite gravity data, it is not possible to perfectly localize the target area, since an infinite number of spherical harmonics would be needed to build a perfect localizing filter, with a value of 1 inside the study area and 0 outside. Consequently, water height estimates from a truncated spherical harmonic spectrum will never be perfectly localized. Contrarily, a filter with a perfect spectral localization, such as that realized by a cumulative spherical harmonic spectrum, is associated with a highly oscillating spatial window. The construction of local basin filters is extensively discussed in the literature (e.g. Swenson and Wahr 2002; Seo and Wilson 2005).

Let us denote $W_{l m}{ }^{c}, W_{l m}{ }^{s}$ and $h_{l m}{ }^{c}, h_{l m}{ }^{s}$ the coefficients of the spherical harmonic expansion of the filter and the water height, respectively. The average water height within the approximate shape of the basin, resulting from the truncation at degree $L$ of the spherical harmonic expansion of $W$, is given by:

$$
\bar{h}=\frac{1}{\Omega} \int h^{L}(\theta, \varphi) \cdot W^{L}(\theta, \varphi) \cdot \sin \theta d \theta d \varphi
$$

where $\Omega$ is the solid angle subtended by the basin, equal to $4 \pi \frac{S_{\text {Area }}}{S_{\text {Earth }}}$, where $S_{\text {Area }}$ is the surface of the area and $S_{\text {Earth }}$ the surface of the Earth. From the orthogonality of the spherical harmonics, one obtains:

$$
\bar{h}=\frac{1}{\Omega} \sum_{\ell=0}^{L} \sum_{m=0}^{\ell}\left(W_{\ell m}^{c} \cdot h_{\ell m}^{c}+W_{\ell m}^{s} \cdot h_{\ell m}^{s}\right)
$$

Now, let us denote as $\delta h_{l m}{ }^{c}$ and $\delta h_{l m}{ }^{s}$ the errors on the spherical harmonics coefficients of the water height measured by a satellite gravity mission, and $\sigma_{\ell}^{2}=\sum_{m=0}^{\ell}\left(\left(\delta h_{\ell m}^{c}\right)^{2}+\left(\delta h_{\ell m}^{s}\right)^{2}\right)$ the degree variance. To simplify the expressions, we suppose that $\delta h_{I m}{ }^{c}$ and $\delta h_{l^{\prime} m^{\prime}}{ }^{s}$ are uncorrelated for any degrees and orders, and $\delta h_{l m}{ }^{c}$ and $\delta h_{l^{\prime} m^{\prime}}{ }^{c}$ (resp. $\delta h_{l m}{ }^{s}$ and $\delta h_{I^{\prime} m}{ }^{s}$ ) are uncorrelated if $\ell \neq \ell^{\prime}$ or $m \neq m^{\prime}$. We 
make the approximation that $\left(\delta h_{\ell m}^{c}\right)^{2}=\left(\delta h_{\ell m}^{s}\right)^{2}=\frac{\sigma_{\ell}^{2}}{2 \ell+1}$. The variance on the average water height resulting from the errors $\delta h_{l m}{ }^{c}$ and $\delta h_{l m}{ }^{s}$ can then be written:

$$
\operatorname{var}(\bar{h})=\frac{1}{\Omega^{2}} \sum_{\ell=0}^{L} \frac{\sigma_{\ell}^{2}}{2 \ell+1} \sum_{m=0}^{\ell}\left(\left(W_{\ell m}^{c}\right)^{2}+\left(W_{\ell m}^{s}\right)^{2}\right)
$$

Introducing the degree spectrum of the localizing filter $W_{\ell}=\sqrt{\sum_{m=0}^{\ell}\left(\left(W_{\ell m}^{c}\right)^{2}+\left(W_{\ell m}^{s}\right)^{2}\right)}$, we end-up with:

$$
\operatorname{var}(\bar{h})=\frac{1}{\Omega^{2}} \sum_{\ell=0}^{L} \frac{\sigma_{\ell}^{2}}{2 \ell+1} W_{\ell}^{2}
$$

If we use a localizing window shaped as an axisymmetric Gaussian bell, then the spectrum $W_{l}$ is given in Wahr et al. (1998), based on Jekeli (1981). However, this Gaussian is normalized so that its global integral is equal to unity. Thus, to be used in equation (4), the $W_{l}$ coefficients given in equation (34) of Wahr et al. (1998) should be divided by the normalization factor $\frac{b}{2 \pi} \frac{1}{1-e^{-2 b}}$, with $b=\frac{\ln (2)}{1-\cos (r / a)}, a$ the semi-major axis of the Earth' s ellipsoid $(a=6378136.46$ $m$ ), and $r$ the distance at the Earth' s surface for which the value of the Gaussian window is equal to half its maximum. 


\section{A.3 The e.motion science team}

J. Bamber ${ }^{1}$, R. Biancale ${ }^{2}$, M. van den Broeke ${ }^{3}$, T. van Dam $^{4}$, K. Danzmann ${ }^{5}$, M. Diament ${ }^{6}$,

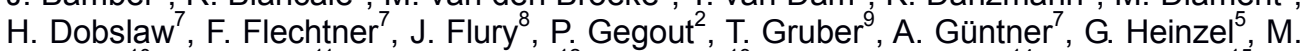
Horwath $^{10}$, J. Huang ${ }^{11}$, C.W. Hughes ${ }^{12}$, A. Jäggi ${ }^{13}$, J. Johannessen ${ }^{14}$, P. Knudsen ${ }^{15}$, J. Kusche $^{16}$, B. Legresy ${ }^{10}$, F. Migliaccio ${ }^{17}$, R. Pail ${ }^{9}$, I. Panet ${ }^{18,6}$, G. Ramillien ${ }^{2}$, M-H. Rio ${ }^{19}$, R. Sabadini $^{20}$, I. Sasgen ${ }^{7}$, H. Savenije ${ }^{21}$, L. Seoane ${ }^{2}$, B. Sheard ${ }^{5}$, M. Sideris ${ }^{22}$, N. Sneeuw ${ }^{23}$, D. Stammer ${ }^{24}$, M. Thomas ${ }^{7}$, B. Vermeersen ${ }^{25}$, P. Visser ${ }^{25}$, S. Vitale ${ }^{26}$, P. Woodworth ${ }^{12}$

${ }^{1}$ University Bristol, Bristol Glaciology Centre, Bristol, United Kingdom

${ }^{2}$ Observatoire Midi-Pyrénées, Groupe de Recherche de Géodésie Spatiale, Toulouse, France

3 Utrecht University, Institute for Marine and Atmospheric Research, Utrecht, The Netherlands

4 Université du Luxembourg, Faculté des Sciences, de la Technologie et de la Communication, Luxembourg

${ }^{5}$ Max-Planck Institut für Gravitationsphysik, Albert-Einstein Institut, Hannover, Germany

${ }^{6}$ Institut de Physique du Globe de Paris, Paris, France

${ }^{7}$ German Research Centre for Geosciences (GFZ), Potsdam, Germany

8 Leibnitz Universität Hannover, Centre for Quantum Engineering and Space-Time Research, Hannover, Germany

9 Technische Universität München, Institut für Astronomische und Physikalische Geodäsie, Münich, Germany

${ }^{10}$ Laboratoire d'Études en Géophysique et Océanographie Spatiales, Toulouse, France

${ }^{11}$ National Resources Canada, Ottawa, Canada

${ }^{12}$ National Oceanography Centre, Liverpool, United Kingdom

${ }^{13}$ Universität Bern, Astronomisches Institut, Bern, Switzerland

${ }^{14}$ Nansen Environmental and Remote Sensing Center, Bergen, Norway

${ }^{15}$ Technical University of Denmark, National Space Institute, Copenhagen, Denmark

${ }^{16}$ Universität Bonn, Institut für Geodäsie und Geoinformation, Bonn, Germany

${ }^{17}$ Politecnico di Milano, Dipartimento di Ingegneria Idraulica, Ambientale, Infrastrutture Viarie, Rilevamento, Milano, Italy

${ }^{18}$ Institut National de l'Information Géographique et Forestière, Marne-la-Vallée, France

${ }^{19}$ Collecte Localisation Satellites, Ramonville-Saint-Agne, France

${ }^{20}$ Università degli Studi di Milano, Milano, Italy

${ }^{21}$ Delft University of Technology, Water Resources Section, Delft, The Netherlands

${ }^{22}$ University of Calgary, Department of Geomatics Engineering, Calgary, Canada

${ }^{23}$ Universität Stuttgart, Geodätisches Institut, Stuttgart, Germany

${ }^{24}$ Universität Hamburg, Zentrum für Marine und Atmosphärische Wissenschaften, Hamburg, Germany

25 Delft University of Technology, Astrodynamics and Satellite Systems, Delft, The Netherlands

${ }^{26}$ University of Trento, Department of Physics, Trento, Italy 


\section{References}

Barletta VR, Sabadini R, Bordoni A (2008) Isolating the PGR signal in the GRACE data: impact on mass balance estimates in Antarctica and Greenland. Geophysical Journal International 172:18-30. doi: 10.1111/j.1365246X.2007.03630.x

Barletta VR, Bordoni A (2009) Clearing observed PGR in GRACE data aimed at global viscosity inversion: Weighted Mass Trends technique. Geophysical Research Letters 36:L02305. doi:10.1029/2008GL036429

Beutler G, Rummel R, Drinkwater MR, von Steiger R (2003) Earth gravity field from space - from sensors to Earth sciences. Space Science Series of ISSI, 17, Kluwer Academic Publishers, Dordrecht, The Netherlands, ISBN 1-40201408-2

Bingham RJ, Hughes CW (2008a) The relationship between sea-level and bottom pressure variability in an eddy-permitting ocean model. Geophys Res Lett 35:L03602. doi:10.1029/2007GL032662

Bingham RJ, Hughes CW (2008b) Determining North Atlantic meridional transport variability from pressure on the western boundary: A model investigation. J Geophys Res 114:C09008

Bingham RJ, Hughes CW (2009) Signature of the Atlantic meridional overturning circulation in sea level along the east coast of North America. Geophys Res Lett 36:L02603. doi: 10.1029/2008GL036215

Cazenave A et al. (2009) Sea level budget over 2003-2008: A re-evaluation from GRACE space gravimetry, satellite altimetry and Argo. Global and Planetary Change 65(1-2):83-88

Cazenave A, Chen J (2010) Time-variable gravity from space and present-day mass redistribution in the Earth system. Earth and Planetary Science Letters 298:263-274. doi:10.1016/j.epsl.2010.07.035

Cazenave A, Llovel W (2010) Contemporary sea level rise. Ann Rev Mar Sci 2:145-173

Chambers DP, Tamisiea ME, Nerem RS, Ries JC (2007) Effects of ice melting on GRACE observations of ocean mass trends. Geophys Res Lett 34:L05610

Chen JL, Wilson CR, Tapley BD, Blankenship DD, Ivins ER (2007) Patagonia 
Icefield melting observed by Gravity Recovery and Climate Experiment (GRACE). Geophys Res Lett 34:L22501. doi10.1029/2007GL031871

Chen JL, Wilson CR, Blankenship D and Tapley BD (2009) Accelerated Antarctic ice loss from satellite gravity measurements. Nature Geosciences doi:10.1038/NGEO694

de Viron O, Panet I, Mikhailov V, van Camp M, Diament M. (2008) Retrieving earthquake signature in GRACE gravity solutions. Geophysical Journal International 174(1):14-20. doi10.1111/j.1365-246X.2008.03807.x

Dexter P, Summerhayes CP (2010) Ocean observations - the Global Ocean Observing System (GOOS). In: Pugh D and Holland G (eds.) Troubled Waters: Ocean Science and Governance, CUP, Cambridge, pp 161-178

Dickey J et al. (1997) Satellite gravity and the geosphere. US National Research Council, National Academy Press, Washington DC

Famiglietti JS, Lo M, Ho SL, Bethune J, Anderson KJ, Syed TH, Swenson SC, de Linage CR, Rodell M (2011) Satellites measure recent rates of groundwater depletion in California's Central Valley. Geophys Res Lett 38:L03403. doi:10.1029/2010GL046442

Flury J, Rummel R (2005) Future satellite gravimetry and Earth dynamics. Springer, Dordrecht, The Netherlands, ISBN 0-387-29796-0

GCOS (Global Climate Observing System) (2003) The Second Report on the Adequacy of the Global Observing Systems for Climate in Support of the UNFCCC. GCOS Report 82, WMO/TD-No 1143

GCOS (Global Climate Observing System) (2006) Systematic observation requirements for satellite-based products for climate, GCOS Report 107, WMO/TD-No 1338

Güntner A (2008) Improvement of global hydrological models using GRACE data. Surveys in Geophysics 29:375-397. doi 10.1007/s10712-008-9038-y

Hager BH (1991) Mantle viscosity - a comparison of models from postglacial rebound and from the geoid, plate driving forces, and advected heat flux. In: Glacial Isostasy, Sea Level and Mantle Rheology, Kluwer Acad., Dordrecht, The Netherlands, pp 493-513

Han SC, Shum CK, Bevis M, Ji C, Kuo C-Y (2006) Crustal dilatation observed by GRACE after the 2004 Sumatra-Andaman Earthquake. Science 313:658 
Hughes T (1973) Is the West Antarctic Ice Sheet Disintegrating ? J. Geophys. Res. 78(33):7884-7910

Hughes CW, de Cuevas BA (2001) Why western boundary currents in realistic oceans are inviscid: A link between form stress and bottom pressure torques. Journal of Physical Oceanography 31:2871-2885. doi:10.1175/15200485(2001)031h2871:WWBCIRi2.0.CO;2

IPCC, 2007, Climate Change (2007). The Physical Science Basis (ed Solomon, S. et al.). Cambridge Univ. Press

Jekeli C (1981) Alternative methods to smooth the Earth's gravity field. Rep. 327, Dep Of Geod Sci and Surv, Ohio State Univ, Columbus

Johannessen $\mathrm{J}$ and the e.motion science team (2010) Earth System Mass Transport Mission, Proposal for Earth Explorer Opportunity Mission EE8. In response to the Call for Proposals for Earth Explorer Opportunity Mission EE8 (ESA/EXPLORER/COM-3/EE-8 October 2009)

Koop R, Rummel R (2008) The future of satellite gravimetry. Report from the Workshop on The Future of Satellite Gravimetry, 1-13 April 2007, ESTEC, Noordwijk, The Netherlands; Institute of Advanced Study, TU Münich

Kusche J, Klemann V, Bosch W (2012) Mass distribution and mass transport in the Earth system. J Geodyn. doi:10.1016/j.jog.2012.03.003

Lettenmaier D, Famiglietti J (2006) Water from on high. Nature 444:562-563

Loomis BD, Nerem RS, Luthcke SB (2011) Simulation study of a follow-on gravity mission to GRACE. Journal of Geodesy. doi:10.1007/s00190-011-0521-8

Meier MF, Dyurgerov MB, Rick UK, O'Neel S, Pfeffer, WT et al (2007) Glaciers dominate Eustatic sea-level rise in the $21^{\text {st }}$ century. Science $317: 1064-67$

Mikhailov V, Tikhotsky S, Diament M, Panet I, Ballu V (2004) Can tectonic processes be recovered from new satellite gravity data?, Earth and Planetary Science Letters 228:281-297

Milne GA, Gehrels, WR, Hughes CW, Tamisiea ME (2009) Identifying the causes of sea-level change. Nature Geoscience 2:471-478

Mitrovica JX, Forte AM (1997) Radial profile of mantle viscosity: results from the joint inversion of convection and post-glacial rebound observables. J. 
Geophys. Res. 102(B2):2751-2770

Oki T, Sud Y (1998) Design of total runoff integrating pathways (TRIP) - A global river channel network. Earth Interactions 2(1):1-36

Pail R et al (2011) First GOCE gravity field models derived by three different approaches. J Geod 85:819-843. doi:10.1007/s00190-011-0467-x

Panet I, Pollitz F, Mikhailov V, Diament M, Banerjee P, Grijalva K (2010) Upper mantle rheology from GRACE and GPS post-seismic deformation after the 2004 Sumatra-Andaman earthquake. Geochemistry, Geophysics, Geosystems 11(6):Q06008. doi:10.1029/2009GC002905

Paulson A, Zhong S, Wahr J (2007) Inference of mantle viscosity from GRACE and relative sea level data. Geophys J Int 171:497-508

Plag H-P, Pealrman M (2009) Global Geodetic Observing System, meeting the requirements of a global society on a changing planet in 2020. Springer, ISBN 978-3-642-02686-7

Pollitz F, Wicks C, Thatcher W (2001) Mantle flow beneath a continental strikeslip fault: post-seismic deformation after the 1999 Hector Mine earthquake. Science 293:1814-1818

Pritchard HD, Ligtenberg SRM, Fricker HA, Vaughan DG, van den Broeke MR, Padman L (2012) Antarctic ice-sheet loss driven by basal melting of ice shelves. Nature 484:502-505. doi:10.1038/nature10968

Ramillien G, Famiglietti J, Wahr J (2008) Detection of continental hydrology and glaciology signals from GRACE: a review. Surveys in Geophysics, Special Issue: Hydrology from Space. doi:10.1007/s10712-008-9048-9

Rignot E, Thomas RH (2002) Mass balance of polar ice sheets. Science 297:1502-1506. doi:10.1126/science. 1073888

Rignot E, Kanagaratnam P (2006) Changes in the Velocity Structure of the Greenland Ice Sheet. Science 311(5763):986-990. doi:10.1126/science. 1121381

Rignot E, Bamber JL, Van Den Broeke MR, Davis C, Li Y, Van De Berg WJ, Van Meijgaard E (2008) Recent Antarctic ice mass loss from radar interferometry and regional climate modelling. Nature Geosciences 1(2):106-110

Rodell M., Famiglietti JS (1999) Detectability of variations in continental water 
storage from satellite observations of the time dependent gravity field. Water Resour. Res. 35, 2705-2724. doi:10.1029/1999WR900141

Rodell M, Velicogna I, Famiglietti J (2009) Satellite-based estimates of groundwater depletion in India. Nature 460:999-1002. doi:10.1038/nature08238

Roussenov V, Williams RG, Hughes CW, Bingham R (2008) Boundary wave communication of bottom pressure and overturning changes for the North Atlantic. Journal of Geophysical Research 114:C08042. doi:10.1029/2007JC004501

Rummel R (2005) Geoid and gravity in Earth sciences - an overview. Earth, Moon and Planets 94(1-2):3-11. doi:10.1007/s11038-005-3755-8

Rummel R (2011) GOCE gravitational gradiometry. J Geod 85:777-790. doi:10.1007/s00190-011-0500-0

Sasgen I, Dobslaw H, Martinec Z, Thomas M (2010) Satellite gravimetry observation of Antarctic snow accumulation related to ENSO. Earth and Planetary Science Letters 299(3-4):352-358

Sasgen I, Klemann V, Martinec Z (2012) Toward the inversion of GRACE gravity fields for present-day ice-mass changes and glacial-isostatic adjustment in North America and Greenland. J Geodyn. doi:10.1016/j.jog.2012.03.004

Schmidt R, Schwintzer P, Flechtner F, Reigber C, Güntner A, Döll P, Ramillien G, Cazenave A, Petrovic S, Jochmann $\mathrm{H}$, et al (2006) GRACE observations of changes in continental water storage. Global and Planetary Change 50:112126

Schmidt R, Flechtner F, Meyer U, Neumayer K-H, Dahle C, König R, Kusche J (2008) Hydrological signals observed by the GRACE satellites. Surveys in Geophysics 29:319-334. doi:10.1007/s107/12-008-9033-3

Seo KW, Wilson CR (2005) Simulated estimation of hydrological loads from GRACE. J Geod 78:442-456. doi:10.1007/s00190-004-0410-5

Sheard B, Heinzel G, Danzmann K, Shaddock DA, Klipstein WM, Folkner WM (2012) Intersatellite laser ranging instrument for the GRACE follow-on mission. Journal of Geodesy. doi: 10.1007/s00190-012-0566-3

Sneuuw N, Flury J, Rummel R (2005) Science requirements on future missions and simulated mission scenarios. Earth, Moon and Planets 94:113-142 
Swenson S, Wahr J (2002) Methods for inferring regional surface-mass anomalies from GRACE measurements of time-variable gravity. J Geophys Res 107(B9):2193. doi:10.1029/2001JB000576

Tapley BD, Bettadpur S, Watkins M, Reigber C (2004) The gravity recovery and climate experiment: mission overview and early results. Geophys Res Lett 31(9):L09607. doi:10.1029/2004GL019920

Tamisiea ME, Leuliette EW, Davis JL, Mitrovica JX (2005) Constraining hydrological and cryospheric mass flux in southeastern Alaska using spacebased gravity measurements. Geophys Res Lett 32:L20501. doi:10.1029/2005GL023961

Tamisiea ME, Mitrovica JX, Davis JL (2007) GRACE gravity data constrain ancient ice geometries and continental dynamics over Laurentia. Science 316:881. doi:10.1126/science. 1137157

Tamisiea ME (2011) Ongoing glacial isostatic contributions to observations of sea level change. Geophys J Int 186:1036-1044. doi:10.1111/j.1365246X.2011.05116.x

Thomas RH, Sanderson JO, Rose KE (1979) Effect of climate warming on the West Antarctic ice sheet. Nature 277:355-358

Van den Broeke MR, Bamber J, Ettema J, Rignot E, Schrama E, van de Berg WJ, van Meijgaard E, Velicogna I, Wouters B (2009) Partitioning recent Greenland mass loss. Science 326:984-986

Van der Wal W, Wu P, Sideris MG, Shum CK (2008) Use of GRACE determined secular gravity rates for glacial isostatic adjustment studies in North-America. J Geodyn 46 (3-5):144-154

Velicogna I (2009) Increasing rates of ice mass loss from the Greenland and Antarctic ice sheets revealed by GRACE. Geophysical Research Letters 36:L19503. doi:10.1029/2009GL040222

Vermeersen BLA (2005) Challenges from solid Earth dynamics for satellite gravity field missions in the post-GOCE era. Earth, Moon and Planets 94:31-40. doi:10.1007/s11038-004-6816-5

Visser PNAM, Sneuuw N, Reubelt T, Losch M, van Dam T (2010) Space-borne gravimetric satellite constellations and ocean tides: aliasing effects. Geophys J Int 181:789-805. doi:10.1111/j.1365-246X.2010.04557.x 
Wahr J, Molenaar M, Bryan F (1998) Time variability of the Earth's gravity field: hydrological and oceanic effects and their possible detection using GRACE. J Geophys Res 103:30205-30230. doi:10.1029/98JB02844

Wahr J, Davis JL (2002) Geodetic constraints on Glacial Isostatic Adjustment. In J.X. Mitrovica and L.L.A.Vermeersen (eds), Ice Sheets, Sea Level and the Dynamic Earth, Geodynamic Series, AGU, Washington, 29, 2-32

Wiese D, Nerem R, Lemoine F (2012) Design configurations for a dedicated gravity recovery satellite mission consisting of two pairs of satellites. Journal of Geodesy 86(2):81-98. doi:10.1007/s00190-011-0493-8

Wouters B, Chambers D, Schrama EJO (2008) GRACE observes small-scale mass loss in Greenland. Geophysical Research Letters 35:L20501. doi:10.1029/2008GL034816

Wu P, Peltier WR (1983) Glacial isostatic adjustment and the free air gravity anomaly as a constraint on deep mantle viscosity. Geophys. J. R. Astron. Soc. $74: 377-450$

Zlotnicki V, Wahr J, Fukumori I, Song Y-T (2007) Antarctic Circumpolar Current transport variability during 2003-2005 from GRACE. J Physical Oceanog 37(2):230-244

Zwally HJ, Abdalati W, Herring T, Larson K, Saba J, Steffen K (2002) Surface melt-induced acceleration of Greenland ice-sheet flow. Science 297:218-222. doi:10.1126/science. 1072708 


\section{Tables}

\begin{tabular}{|c|c|c|c|}
\hline Research objectives & Time scales & $\begin{array}{l}\text { Expected signals: } \\
\text { temporal variation in EWH, geoid, } \\
\text { gravity }\end{array}$ & Precision, resolution \\
\hline $\begin{array}{l}\text { Continental water storage } \\
\text { variations }\end{array}$ & $\begin{array}{l}\text { weeks to } \\
\text { decades }\end{array}$ & $\begin{array}{l}\text { several dm EWH } \\
m m \text { to } \mathrm{cm} \mathrm{EWH} \mathrm{/} \mathrm{y}\end{array}$ & $\begin{array}{l}1 \text { cm EWH @ } 400 \text { km, } \\
10 \text { cm EWH @ } 200 \text { km } \\
1 \text { mm EWH/y @ 400km }\end{array}$ \\
\hline Ice sheets mass balance & $\begin{array}{l}\text { months to } \\
\text { decades }\end{array}$ & $\begin{array}{l}\mathrm{dm} \text { to } \mathrm{m} \text { EWH } \\
\mathrm{dm} \mathrm{EWH} / \mathrm{y}\end{array}$ & $\begin{array}{l}1 \text { cm EWH @ } 400 \text { km, } \\
10 \text { cm EWH @ } 200 \text { km } \\
1 \text { mm EWH/y @ 400km }\end{array}$ \\
\hline $\begin{array}{l}\text { Oceanic mass variations / } \\
\text { sea level }\end{array}$ & $\begin{array}{l}\text { hours to } \\
\text { decades }\end{array}$ & $\begin{array}{l}\mathrm{cm} \text { to } \mathrm{dm} \text { EWH } \\
\mathrm{mm} \text { to } \mathrm{cm} \mathrm{EWH} \mathrm{/} \mathrm{y}\end{array}$ & $\begin{array}{l}5 \text { mm EWH @ } 500 \text { km, } \\
1 \text { mm EWH / y @ global scale }\end{array}$ \\
\hline $\begin{array}{l}\text { Glacial isostatic } \\
\text { adjustment }\end{array}$ & secular & $2 \mathrm{~mm}$ geoid/y & 0.01 mm geoid/y @ 400km \\
\hline $\begin{array}{l}\text { Earthquakes (Mw 7-8) } \\
\text { Coseismic }\end{array}$ & instantaneous & 0.1 to $1 \mathrm{~mm}$ geoid or $5 \mu \mathrm{Gal}$ & $\begin{array}{l}0.1 \mu \mathrm{Gal} @ 200 \mathrm{~km} \text { or } \\
0.1 \mathrm{~mm} \text { geoid @ } 400 \text { km }\end{array}$ \\
\hline $\begin{array}{l}\text { Earthquakes (Mw 7-8) } \\
\text { Post-seismic }\end{array}$ & to decades & $\begin{array}{l}0.01 \text { to } 0.1 \mathrm{~mm} \text { geoid } / \mathrm{y} \text { or } 0.5 \\
\mu \mathrm{Gal} / \mathrm{y}\end{array}$ & $\begin{array}{l}0.01 \mu \mathrm{Gal} / \mathrm{y} @ 200 \mathrm{~km} \text { or } \\
0.01 \mathrm{~mm} / \mathrm{y} \text { geoid @ } 400 \text { km }\end{array}$ \\
\hline $\begin{array}{l}\text { Mantle convection \& } \\
\text { plate tectonics }\end{array}$ & $\begin{array}{l}\text { decades to } \\
\text { secular }\end{array}$ & $0.05 \mathrm{~mm}$ geoid / yr & 0.01 mm geoid /yr @ 400 km \\
\hline $\begin{array}{l}\text { Height reference, orbits, } \\
\text { combination of } \\
\text { observation techniques }\end{array}$ & $\begin{array}{l}\text { hours to } \\
\text { decades }\end{array}$ & $\begin{array}{l}\text { few cm geoid } \\
\text { few mGal }\end{array}$ & $\begin{array}{l}1 \text { mm geoid @ } 200 \text { km } \\
1 \mu \mathrm{Gal} @ 200 \text { km }\end{array}$ \\
\hline
\end{tabular}

Table 1 Overview of science requirements to be addressed by e.motion 


\begin{tabular}{|c|c|}
\hline Gaussian bell radius & Geoid variation \\
\hline $2000 \mathrm{~km}$ & $0.44 \mathrm{~mm}$ \\
$800 \mathrm{~km}$ & $0.27 \mathrm{~mm}$ \\
$400 \mathrm{~km}$ & $0.13 \mathrm{~mm}$ \\
$200 \mathrm{~km}$ & $0.08 \mathrm{~mm}$ \\
$100 \mathrm{~km}$ & $0.04 \mathrm{~mm}$ \\
\hline
\end{tabular}

Table 2 Geoid effect of water loads with a spatial distribution as a Gaussian bell of varying radii 


\section{Figures}

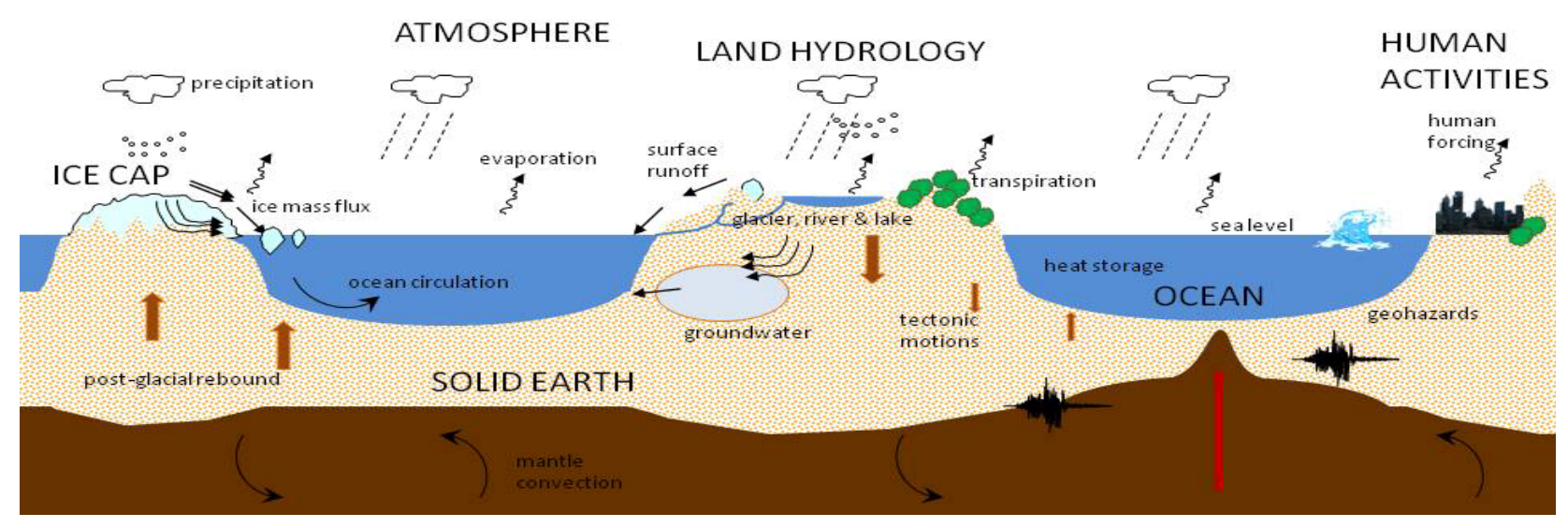

Fig. 1 Processes in the Earth system involving mass transport, mass variations and mass exchange within and between individual system components 

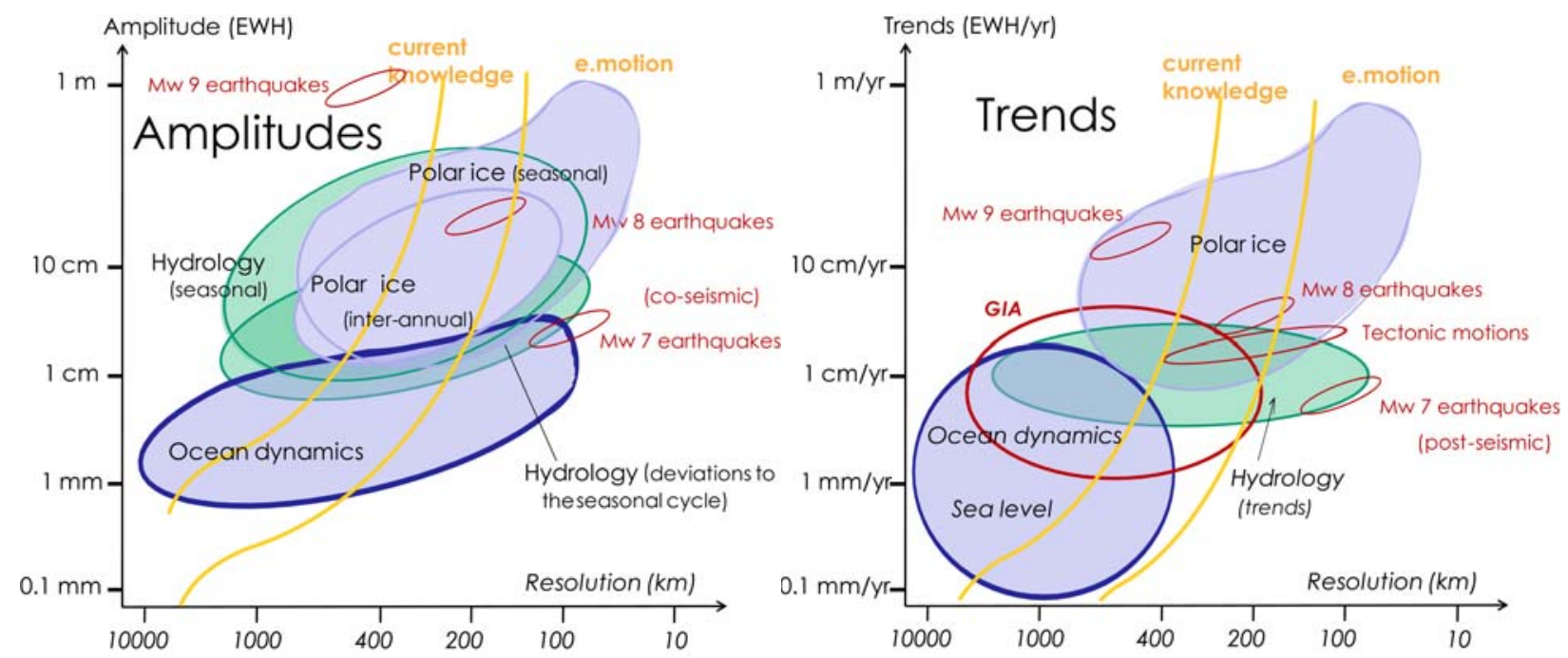

Fig. 2 Signal amplitudes of mass variations in equivalent water height $(E W H)$ as a function of spatial resolution, together with present-day accuracy and resolution and with expected e.motion performance. Solid Earth mass variations are converted to EWH. Contributions from seasonal to inter-annual variations are given on the left panel, and contributions from long-term trends are plotted on the right panel. Axes are given in logarithmic scales but expanded in the 100-1000 $\mathrm{km}$ interval and in the $1 \mathrm{~m}(/ \mathrm{yr})-10 \mathrm{~cm}(/ \mathrm{yr})$ interval in order to emphasize signals at scales of hundreds of $\mathrm{km}$ and amplitudes of tens of $\mathrm{cm}$ detectable with satellite gravity missions 


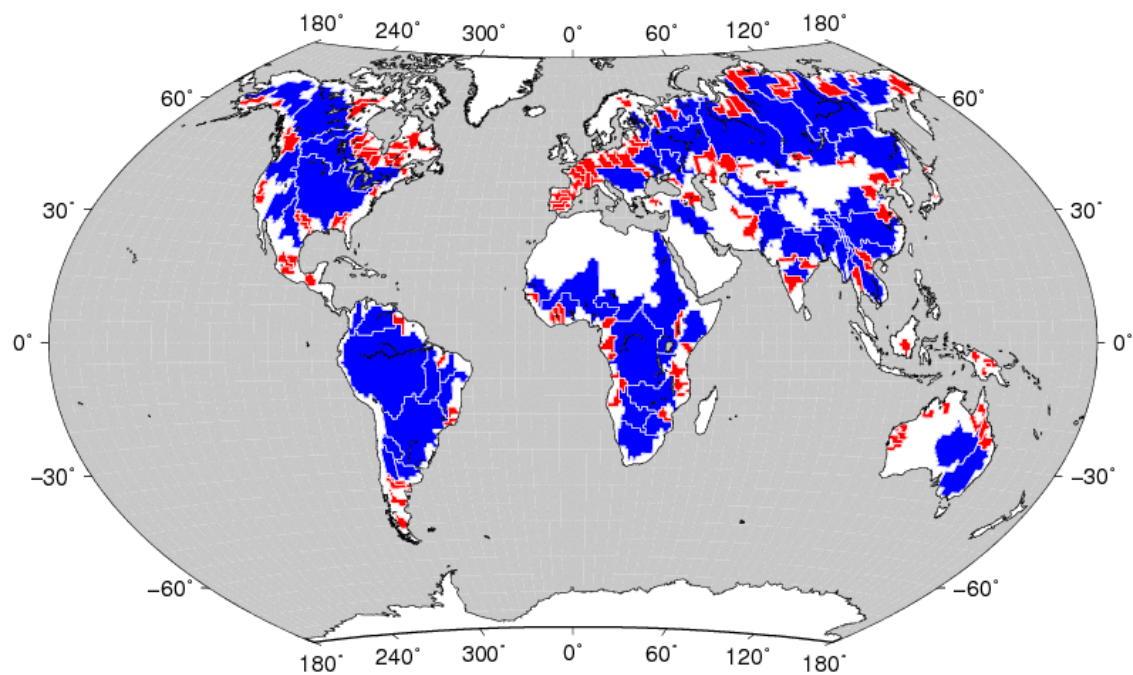

Fig. 3 River drainage basins with a size between $40000 \mathrm{~km}^{2}$ and $200000 \mathrm{~km}^{2}$ (in red, from Oki and Sud 1998) that could be resolved by e.motion, as well as basins larger than $200000 \mathrm{~km}^{2}$, which corresponds to the present day resolution. e.motion will also recover sub-basin variability, which plays an important role for climatic processes

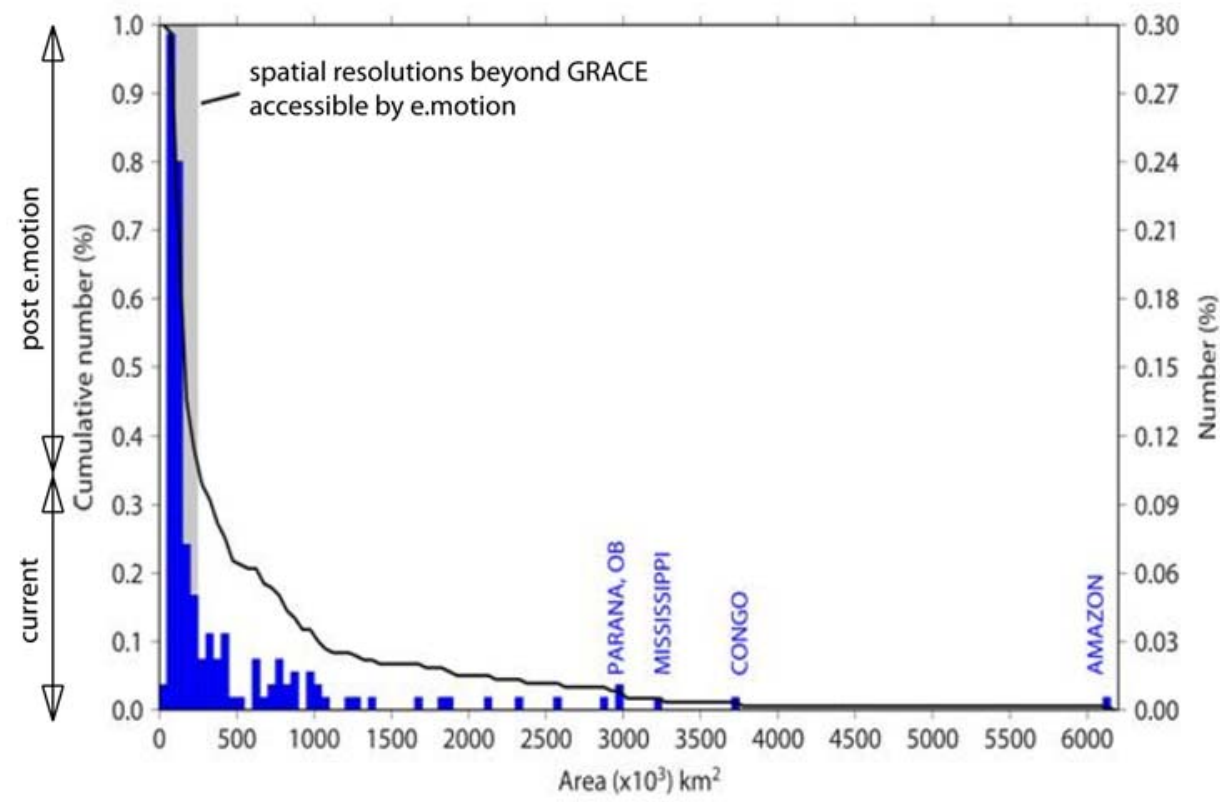

Fig. 4 Distribution of areas of continental hydrology drainage basins (Oki and Sud 1998). The gray area to the left indicates the spatial resolution improvement of e.motion with regard to current knowledge. The black curve indicates the cumulative number of basins. About $33 \%$ of the basins can be studied with GRACE, and almost $100 \%$ with e.motion 


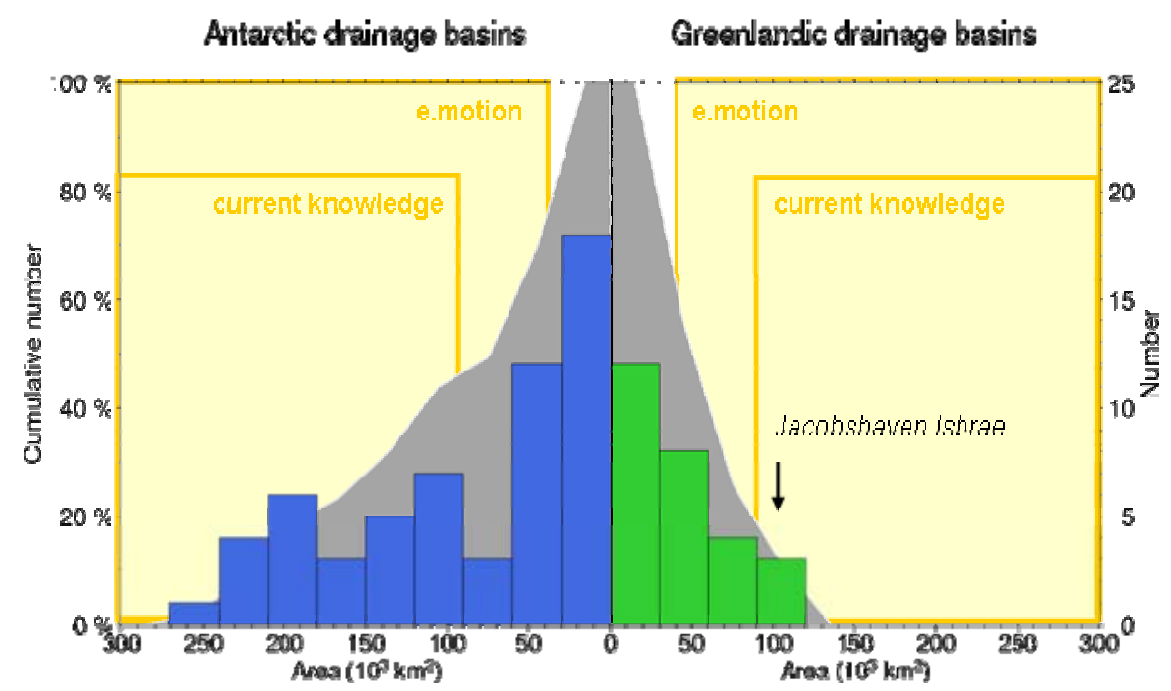

Fig. 5 Distribution of areas of Antarctic (Rignot and Kanagaratnam 2006) and Greenlandic (Rignot et al. 2008) drainage basins and recovery improvement of e.motion with regard to current knowledge. Grey curve indicates the cumulative number of basins

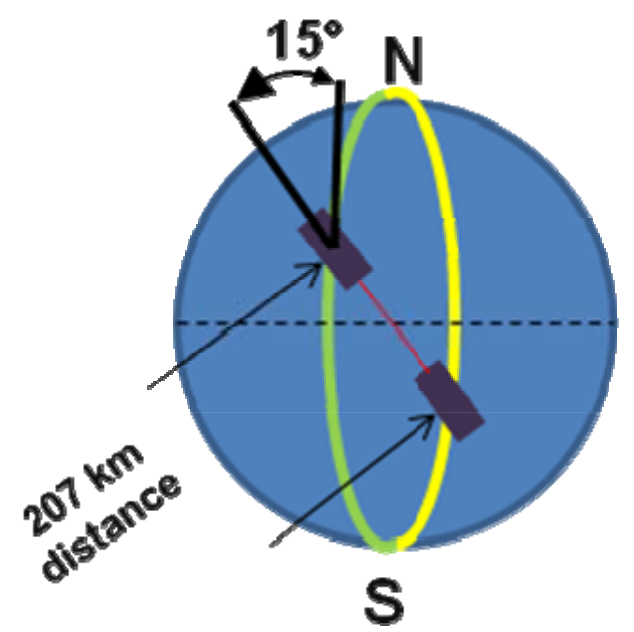

Fig. 6 e.motion pendulum configuration. The two satellites are moving with constant inter-satellite distance, but on two orbital planes slightly rotated relative to each other 


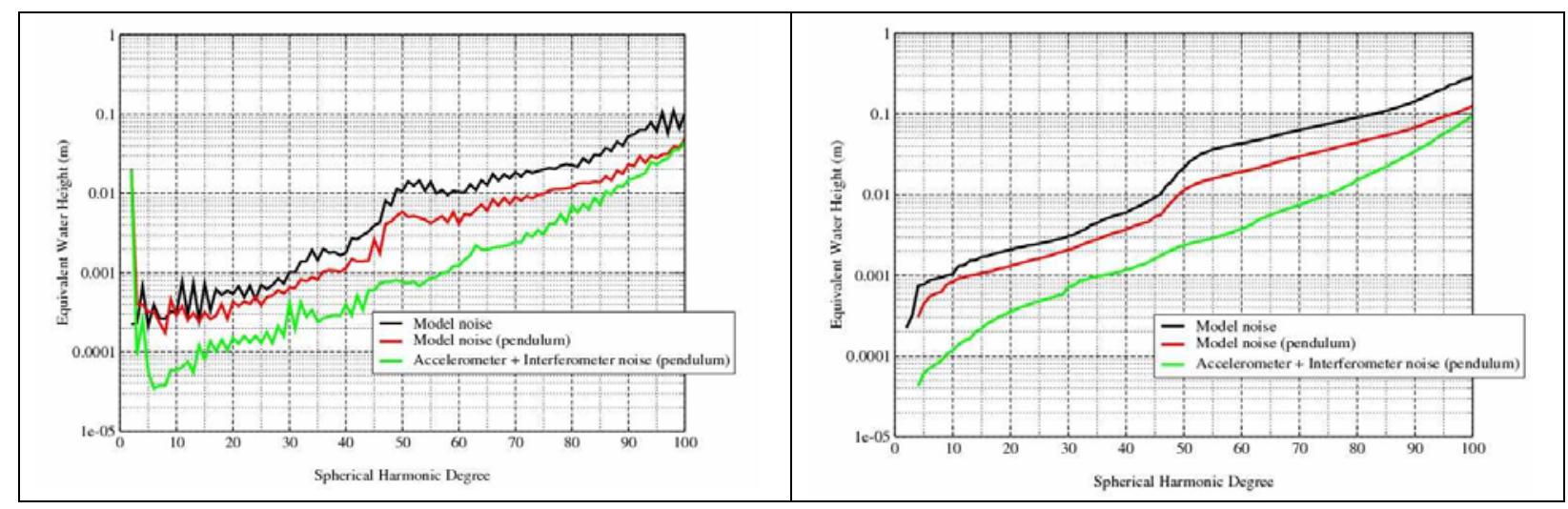

Fig. 7 Left panel: spectra of gravity field errors for each spherical harmonic degree $I$ in terms of water height. The spatial resolution $d$ in kilometers, equal to the half-wavelength, is related to the spherical harmonic degree / following $d=$ 20000/I. Right panel: spectra of gravity field errors in terms of water height, accumulated up to degree $l$. Green curves indicate errors due to the accelerometer and interferometer noise in the e.motion configuration, red curves indicate errors due to imperfect de-aliasing in the e.motion configuration, and black curves indicate errors due to imperfect de-aliasing in a co-planar configuration 